\title{
Assessment of umbilical cord TSH in term Neonates in Manipur
}

\author{
${ }^{1}$ Dr. Sangeeta.N, ${ }^{2}$ Dr. L. Kamala, ${ }^{3}$ Dr. Paras Karki, ${ }^{4}$ Dr. Gomi Basar, \\ ${ }^{5}$ Dr. Y. Ajit Kumar, ${ }^{6}$ Dr. L. Ranbir Singh, ${ }^{7}$ Dr. W. G. Singh, \\ ${ }^{8}$ Dr. M. Amuba Singh \\ ${ }^{I}$ Assistant Professor, Dept. of Biochemistry, RIMS, Imphal, Manipur, India \\ ${ }^{2}$ PhD, Dept. of Biochemistry, RIMS, Imphal, Manipur, India \\ ${ }^{3}$ Ex-Post-Graduate-Trainee, Dept. of Obstetrics \& Gynaecology, RIMS \\ ${ }^{4}$ Post-Graduate-Trainee, Dept. of Biochemistry, RIMS \\ ${ }^{5}$ Registrar, Dept. of Obstetrics \& Gynaecology, RIMS \\ ${ }^{6}$ Professor, Dept. of Paediatrics, RIMS \\ ${ }^{7}$ Professor, Dept. of Biochemistry, RIMS \\ ${ }^{8}$ Professor \& Head Dept. of Biochemistry, RIMS
}

\begin{abstract}
:
Objective: To estimate the level of umbilical cord TSH in term Neonates in Manipur

Study design and setting: Cross-sectional study conducted in the Dept. of Biochemistry in collaboration with Dept. of Pediatrics and Dept. of Obstetrics \&Gynaecology, Regional Institute of Medical Sciences (RIMS), Imphal (Manipur).

Materials and Methods: Blood samples were collected from the umbilical cord of 500 term newborn infants at the time of birth of the baby. Thus a mixed cord blood sample including both from the umbilical artery and vein was obtained and Thyroid stimulating hormone level (TSH) was estimated within 24 hrs by enzyme immunoassay.
\end{abstract}

Results: The birth weights ranged between 2.5 to $4.0 \mathrm{~kg}$. The male: female ratio was 205:295. TSH values ranged from 2.8-52.3mlU/L. The mean value was $13.264 \mathrm{ml} / \mathrm{L}$. A cut -off value of $20 \mathrm{mlU} / \mathrm{L}$ was used for recall testing of complete thyroid profile (T3, T4 and TSH). Forty seven infants were recalled for repeating complete thyroid profile

Key words: Hypothyroidism, TSH, cord blood

\section{Introduction}

Congenital hypothyroidism $(\mathrm{CH})$ is by far the most common preventable cause of mental retardation in infants, accounting $90 \%$ of hypothyroidism cases in infants. $\mathrm{CH}$ occurs when any part of the fetus's thyroid system fails to develop correctly ${ }^{1}$. It is a major preventable cause of mental retardation with an incidence of 1 in 4000 births in various neonatal programme. ${ }^{2}$ Most newborns with $\mathrm{CH}$ show no clear symptoms of the disorder, and could potentially go for months with the disease undetected. Accompanying the overt clinical changes in the infants is the less obvious damage to the brain resulting in mental retardation. Although treatment at this juncture will reverse the clinical signs and symptoms, the damage to the baby's brain is irreversible. The longer the disorder goes unrecognized (and thus untreated) the greater is the insult to the brain. It is thus essential to get the newborns tested for $\mathrm{CH}$ within three months of birth. If the initial screening shows a low level of $\mathrm{T} 4$ hormone and elevated TSH, further test can be done to confirm a diagnosis of hypothyroidism. Few studies are reported regarding the screening for congenital hypothyroidism. Screening for congenital hypothyroidism $(\mathrm{CH})$ is widespread for the last two decades. It has not been able to be implemented in developing countries like India because of several factors like cost, lack of reliable laboratories on a large scale, and non availability of base line data in our population. Use of cord blood TSH as a screening tool is an attractive preposition because of its simplicity and accessibility ${ }^{3}$. Fuse, et al had shown that mixed cord blood is a good sampling technique for screening for $\mathrm{CH}^{4}$. Walfish concluded that cord TSH had a better specificity and sensitivity as compared to cord or filter paper T4 at 3-5 days of age ${ }^{5}$. The present study was designed to estimate the level of TSH in cord blood as a screening test of $\mathrm{CH}$ so that early intervention, follow up and counseling can be given.

\section{Materials and Methods}

The study was carried out from April 2008 to Jun 2009 in the Department of Biochemistry, Regional institute of Medical sciences Imphal, in collaboration with the Department of Pediatrics and Obs. and Gynecology. All the deliveries conducted during the study period form the study group. 
Blood samples were collected in a sterile container drawn from a $15-20 \mathrm{~cm}$ length of the Umbilical cord incised while severing it at the time of birth of the baby. Thus a mixed cord blood sample including both from the umbilical artery and vein was obtained. Babies who were born preterm $(<37 \mathrm{wk})$ or weight $<2.5 \mathrm{Kg}$ or whose mothers were on any thyroid medications were excluded from the study. Records of the mothers age, parity, thyroid status, race, residence, thyroid status, race residence, community, blood pressure, diabetes, use of iodine antiseptics on the mother prior to delivery etc. were kept. The type of medications or anesthesia given , anesthetic agents including doses used, duration of anesthesia given to the mother till birth of the baby, the type of antiseptics used on the mother were also noted. At birth, the baby was resuscitated and examined for weight, sex, time to first cry. APGAR scores were noted. TSH was estimated within $24 \mathrm{hrs}$ by enzyme immunoassay (Micro Well TSH ELISA) using kit provided by HUMAN. Five hundred samples of umbilical cord blood neonates were examined. Forty seven infants were recalled for repeating complete thyroid profile. One baby was finally proved to be hypothyroid after repeat confirmation. There was no dropout among the babies approached for repeat testing.

\section{Results}

Five hundred samples of cord blood were tested for TSH.

Table I - Weight Wise Distribution of Samples for TSH Estimation

\begin{tabular}{|c|c|c|}
\hline Weight & No. of Samples & $\%$ \\
\hline $2.5-2.99 \mathrm{Kg}$ & 170 & 34 \\
\hline $3-3.49 \mathrm{Kg}$ & 240 & 48 \\
\hline $3.5-3.99 \mathrm{Kg}$ & 85 & 17 \\
\hline $4 \mathrm{Kg} \mathrm{\&} \mathrm{above}$ & 5 & 1 \\
\hline
\end{tabular}

The birth weight of the infants ranged between 2.5 to $4.0 \mathrm{~kg}$.

Table II - Cord Blood TSH levels

\begin{tabular}{|c|c|c|}
\hline $\begin{array}{l}\text { Cord TSH } \\
\text { level }(\mathrm{mIU} / \mathrm{L})\end{array}$ & No. of samples & $\%$ \\
\hline$<4$ & 34 & 6.8 \\
\hline $4-7.99$ & 134 & 26.8 \\
\hline $8-11.99$ & 163 & 32.6 \\
\hline $12-15.99$ & 84 & 16.8 \\
\hline $16-19.99$ & 38 & 7.6 \\
\hline $20-24.99$ & 25 & 5 \\
\hline $25-29.99$ & 15 & 3 \\
\hline $30-34.99$ & 1 & 0.2 \\
\hline $35-39.99$ & 1 & 0.2 \\
\hline $40-44.99$ & 1 & 0.2 \\
\hline $45-49.99$ & 2 & 0.4 \\
\hline $50-99.99$ & 2 & 0.4 \\
\hline$>100$ & 0 & 0 \\
\hline
\end{tabular}

TSH values ranged from 2.8-52.3mlU/L. Mean TSH value was $13.26 \mathrm{mIU} / \mathrm{L}$. Forty seven infants were recalled for repeating complete thyroid profile. There was no dropout amongst the babies approach for repeat testing.

Fig I: Sex wise distribution of the cases

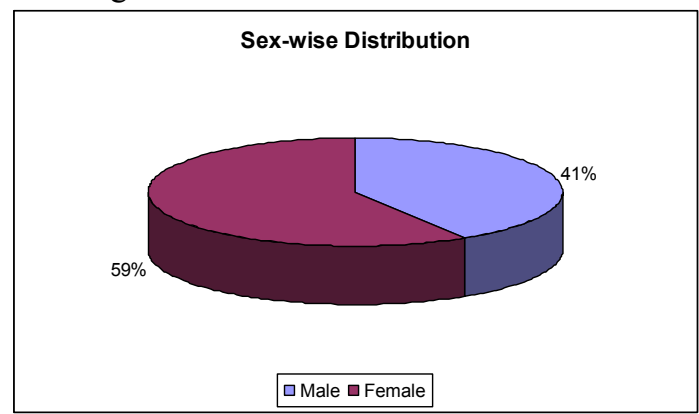

Male: female ratio was 205:295, $41 \%$ males and 59\% females

\section{Discussion}

In our study TSH values ranged from 2.8-52.3mlU/L. Forty seven infants were recalled for repeat complete thyroid profile. One baby was finally proved to be hypothyroid after repeat confirmation. The cord TSH value in that infant was $52.3 \mathrm{mlU} / \mathrm{L}$. TH concentrations are low in the fetus during the first half of 
pregnancy. During this time, the fetus is entirely dependent on maternal TH; its supply to the fetus is controlled by the placenta and the thyroid status of the mother. The fetal hypothalamic - pituitary -thyroid axis begins to function by mid gestation and is mature in the term infant at delivery. Despite the critical importance of TH on multiple organ systems, especially the brain, most infants with $\mathrm{CH}$ appear normal at birth. The hypothyroid fetus appears to be protected at least in part by placental transfer of maternal TH. This was best illustrated by the demonstration that cord blood thyroxine (T4) concentration at birth in those infants unable to synthesize T4 was nonetheless one third to one half that of normal infants ${ }^{6}$.In addition, there is increased intracerebral conversion of to triiodothyronine (T3), resulting in increased local availability of T3 despite the low serum concentrations ${ }^{7}$.

Indeed, normal or near-normal cognitive outcome is possible in even the most severely affected infants with $\mathrm{CH}$. This is true as long as postnatal therapy is early and adequate and maternal thyroid function is normal.

In contrast, when both maternal and fetal hypothyroidism are present, whether attributable to severe iodine deficiency, potent thyrotropin receptor (TSH-R)-blocking antibodies (TRBAbs) (or TSH-blocking immunoglobulin), or maternal-fetal PITI deficiency, there is a significant impairment in neurointellectual development despite adequate therapy soon after birth ${ }^{8,9}$.Maternal hypothyroidism alone during early gestation can lead to mild but significant cognitive impairment of the offspring ${ }^{9,10}$.

Pilot screening programs for $\mathrm{CH}$ were developed in Quebec, Canada, and Pittsburgh, Pennsylvania, in 1974 and have now been established in Western Europe, North America, Japan, Australia, and parts of Eastern Europe, Asia, South America, and Central America ${ }^{11-13}$. In North America, more than 5 million newborns are screened and approximately 1400 infants with $\mathrm{CH}$ are detected annually. Certainly the main objective of screening is the eradication of mental retardation. In addition to the profound clinical benefit, it has been estimated that the cost of screening for $\mathrm{CH}$ is much lower than the cost of diagnosing $\mathrm{CH}$ at an older age. Iodine deficiency remains the most common treatable cause of mental retardation Worldwide. Associated nutritional deficiencies in selenium and iron may have an effect on neurologic development and thyroidal response to iodine therapy ${ }^{14}$. Many countries have initiated salt iodination ${ }^{14-17}$. Although North America is usually considered to be an iodine sufficient area, recent epidemiologic evidence suggest that a number of pregnant women may be iodine deficient ${ }^{18}$. There is also some concern that maternal iodine deficiency may be reappearing in developed countries despite salt iodination because diet- conscious young women may avoid iodine-supplemented salt and bread ${ }^{19,20}$. Iodine supplementation before or during pregnancy will normalized thyroid function in the mother and newborn ${ }^{20,21}$. Although methodology influenced biases can still be present in a few cases (onlyT4 as a screening approach or a high cut-off of the TSH test), according to worldwide data on iodine supply provided by World Health Organization and the activities of the International Council for the Control of Iodine Deficiency Disorders working group, regional differences in $\mathrm{CH}$ incidence are suggesting to be more likely to be due to iodine deficiency thyroid disorders than to ethnic affiliation. In fact, the $\mathrm{CH}$ incidence is lower in countries where the iodine supply is sufficient (e.g. USA 1:4000, Japan 1:5000, Taiwan 1:5700) than in those were iodine supply is deficient Italy, Turkey 1: 2400. Unfortunately, iodine deficiency is still prevalent in a large part of the world; including our country which is characterized by a moderate-mild iodine deficiency.

Our results show that $33.8 \%$ (169 cases) samples showed a cord blood TSH value of $>10 \mathrm{mlU} / \mathrm{L}$. This is less to figures from a study in Ethiopia ${ }^{22}$. Our mean value was $13.264 \mathrm{mlU} / \mathrm{L}$, while Feleke,et al ${ }^{23}$ observed value of $9.6 \mathrm{mIU} / \mathrm{L}$ in 4206 newborns. However, our TSH values were somewhat similar to that found by Khadilkar et al ${ }^{24}$ who, in a study of 203 neonates found a mean cord TSH of $12.3 \mathrm{mlU} / \mathrm{L}$. Arunkumar et.al ${ }^{25}$ who study in 1200 neonates found a mean TSH value $6.13 \mathrm{mIU} / \mathrm{L}$ which is lower compared to our study.

Normal cord TSH values show a wide range of $1.0-28.9 \mathrm{mlU} / 1$ from birth till fourth day in term babies $^{1}$ and we had used a cut of $20 \mathrm{mlU} / \mathrm{L}$ and recall rate was $9.4 \%$, but had we opted for a higher cut-off of 25 , 30 or 40 for recall purposes, our rates would have fallen to $4.4 \%, 1.4 \%$ or $1 \%$ respectively. A 5 -year prospective study from Thailand ${ }^{27}$ used cut-off value of 30 to begin with and had a recall rate of $1.1 \%$ in a large sample size of 35,390 neonates. They subsequently modified their recall policy and raised the cut-off value to 40 leading to a fall in recall rate to $0.43 \%$. Higher cut-off values of cord TSH for recall purposes and thus a lower recall rate will vastly improve the economic and practical logistics in any widely organized public health program particularly so in our country. Our figures have shown a comparable trend as with the normative data for cord blood TSH values as reported by various workers across the globe.

\section{Conclusion}

Congenital hypothyroidism $(\mathrm{CH})$ is the one of the most common preventable causes of mental retardation which can be detected by measuring the level of TSH in the cord blood. We can conclude that we may safely use the widely used cutoff cord blood TSH values of $>20 \mathrm{mlU} / \mathrm{ml}$ for purposes of recall for retesting, through from logistic angles a cut off value of $>30$ or $>40$ may be used. Still population-based studies may be done to achieve more credible guidelines, more so to gauge the incidence and epidemiology of $\mathrm{CH}$ in our country. 


\section{References}

[1]. Kleigman RM, Behrman RE, Stanton BF, editors. Nelson Textbook of Pediatrics. 19 ${ }^{\text {th }}$ ed. Philadelphia: Saunders;2012: 1895-1903

[2]. Newborn screening for congenital hypothyroidism: recommended guidelines,AAP policy statement.Paediatrics 1993:91;1203-1209

[3]. Arun Kumar Manglik ,Nandita Chatterjee and Gautam Ghosh .Umbilical Cord Blood TSH Levels in Term Neonates: A screening tool for congenital hypothyroism,Indian Pediatrics 2005;42:1029-1032

[4]. Fuse Y, Wakae E, Nemoto Y, Uga N, Tanaka M, Maeda M, Tada H, Miyachi Y, Irie M. Inflence of perinatal factors and sampling methods on TSH and thyroid hormone levels in cord blood. Endocrinol Jpn.1991 Jun; 38(3): 297-302.S

[5]. Walfish PG.Evaluation of three thyroid-function screening tests for detecting neonatal hypothyroidism. Lancet.1976 Jun 5; 1(1971): 1208-10.

[6]. Vulsma T, GonsMH,de Vijlder JJ. Maternal-fetal transfer of thyroxine in congenital hypothyroidism due to a total organification defect or thyroid agenesis. N Engl J Med.1989;321: 13-16

[7]. Kester MH.Martinez de MenaR ,ObgeronMJ et al.Iodothyronine levels in human developing brain: major regulatory roles of iododothyronine deiodenases in different areas.J Clin Endocrinol Metab 2004; 24:3117-3128

[8]. Glinoer D. Potential consequences of maternal hypothyroidism on the offspring : evidence and implications. Horm Res 2001:55: $109-114$

[9]. Haddow JE, Palomaki GE, Allan WC et al . Maternal thyroid during pregnancy and consequent neuropsycological development of the child .n Engl J Med . 1999; 341: 549-555

[10]. Morreale de Escober G, Obregon MJ, Escobar del Rey F.Is neuropsychological development related to maternal hypothyroidism or to maternal hypothyroxinemia ? J Clin Endocrinol Metab.2000; 85: 3975-3987

[11]. Dussault JH, Coulombe P, Laberge C,Letarte J,Guyda H, Khoury K. Preliminary report on a mass screening program for neonatal hypothyroidism .J Paediatr.1975; 86:670-674

[12]. Working Group on Neonatal Screening of the European Society for Paediatric Endocrinology . Revised guidelines for neonatal screening programmes for primary congenital hypothyroidism . Horm Res .1999; 52:49-52

[13]. LaFranchi SH, SynderDB, Sesser DE et al. Follow-up of new borns with elevated screening T4 concentrations . J Paediatr . 2003; 143:296-301

[14]. DeLange F, BurgiH, Chen ZP,DunnJT.World status of monitoring iodine deficiency disorders control programs. Thyroid. 2002;12:915-924

[15]. Waller DK, Anderson JL, Lorey F, Cunningham GC. Risk factors for congenital hypothyroidism : an investigation of infants bir th weight, ethnicity and gender in California .1990-1998. Teratology 2006; 62:36-41

[16]. Zimmermann MB, ZederC, ChaoukiN, Saad A, Torresani T, Hurrel RF. Dual fortification of salt with iodine and microencapsulated iron : a randomised, double- blind, controlled trial in Moroccan schoolchildren. Am J Clin Nutr.2003; 77:425432

[17]. Hassanien MH,Hussein LA,Robinson EN, Preston MercerL. Human iodine requirements determined by the saturation kinetics model . J Nutr Biochem. 2003; 14: 280-287

[18]. Hollowell JK, Staching NW,Hannon Whet al .Iodine nutrition in the united states : trends and public health implications - iodine excretion data from National Health and Nutrition examination surveys I and III (1971- 1974 and 1988- 1994).J Clin Endocrinol Metab 1998: 83:3401-3408

[19]. Delange F, de Benoist B , Pretell E, DunnJT. Iodine deficiency in the world : where do we stand at the turn of the century?Thyroid 2001; 11:437-447

[20]. Glinoer D. Pregnancy and iodine . Thyroid . 2001; 11:471-481

[21]. BartalenaL, Bogazzi F, Braverman LE, Martino E. Effects of amiodarone administration during pregnancy on neonatal thyroid function and subsequent neurodevelopment . J Endocrinol Inves .2001;13:1069-1078

[22]. MekennonY,GizachewWH,Chamiso B, Raue F.Thyroid stimulating hormones values in cord blood in neonates.Ethiop J Health Dev 2003;17:125-130

[23]. Feleke Y, Enquoselassie F,Deneke F,Abdulkadir J, Hawariet GW, Tilahun M.Neon etal congenital hypothyroidism screening in Addis Ababa, Ethopia.East Afri Med J 2000;77:377-381.

[24]. Khadilkar V, Khadilkar A, Cowasji H. neonatal thyroid screening program using filter paper methoid Cape News 2002;6:1.

[25]. Arunkumar M, Nandita CH, Goutam G.Umbilical Cord Blood TSH Levels in term neonates:A screening Tool for congenital Hypothyroidism.Indian pediatrics.2005;42:1029-31.

[26]. Agrawal K, Paudel BH, Singh PN, Majhi S, Pokhrel H, Upadhayay N etal. Levels of T4 and TSH in mother's blood and in cord blood at the time of delivery. Health Renaissance 2013;1: 6-10

[27]. Mahachoklertwattana P, Phuaphradit W,Siripoonya P, Charoenpol O, Thuvassethakul P, Rajatnavin R . Five - year thyrotropin screening for congenital hypothyroid in Ramathibodi Hospital .J Med Assoc Thai 1999: 82:S27-S32 